\title{
Pesquisas contemporâneas sobre a condição do negro no Brasil e a universidade: tendências e debates (1988-2016)
}

Contemporary research on black condition in Brazil and the university: trends and debates (1988-2016)

Investigación contemporánea sobre la condición de los negros en Brasil y la universidad: tendencias y debates (1988-2016)

Marcos Antonio Batista da Silva - Centro de Estudos Sociais (CES) - Universidade de Coimbra| Projeto 725402- POLITICS - ERC-2016-COG| Coimbra| Portugal. E-mail: marcossilva@ @es.uc.pt | (1) овсі

Resumo: O presente trabalho propõe oferecer uma síntese de textos selecionados a partir de um amplo levantamento publicado pela Edições Câmara no ano de 2017, sobre a condição do negro no Brasil. Para este estudo, privilegiamos a questão da universidade no contexto das relações étnico-raciais. O estudo reuniu uma bibliografia abrangente e diversificada que serviu para alicerçar a revisão de literatura e a construção de um dos eixos de um o trabalho em andamento no projeto POLITICS - A política de antirracismo na Europa e na América Latina: produção de conhecimento, decisão política e lutas coletivas. O estudo é oportuno para a reflexão e alicerçar novos trabalhos sobre a temática das relações étnico-raciais nas sociedades contemporâneas, aprofundando o conhecimento sobre raça, e antirracismo, proporcionando uma maior compreensão sobre a forma como as injustiças historicamente enraizadas estão a ser questionadas por instituições, em particular a universidade.

Palavras-chave: Relações étnico-raciais. Universidade. Antirracismo.

Abstract: This paper proposes to offer a synthesis of texts selected from a large survey published by Edições Câmara in 2017, about the condition of black people in Brazil. For this study, we favor the university issue in the context of ethnic-racial relations. The study brought together a comprehensive and diverse bibliography that underpinned the literature review and the construction of one of the axes of ongoing work on the POLITICS project - Anti-racism policy in Europe and Latin America: knowledge production, political decision making and collective struggles. The study is timely for reflection and to ground new work on the theme of ethnic-racial relations in contemporary societies, deepening knowledge about race, and antiracism, providing a greater understanding of how historically rooted injustices are being questioned by institutions, in particular the university.

Keywords: Ethnic-racial relations. University. Anti-racism.

- Recebido em 27 de abril de 2018 • Aprovado em 15 de maio de 2019 • e-ISSN: 2177-5796

DOI: http://dx.doi.org/10.22483/2177-5796.2020v22n1p167-188

Copyright @ 2019. Conteúdo de acesso aberto, distribuído sob os termos da Licença Internaonal da CreativeCommons - CC BY-NC-SA Atribuição Não Comercial (https://br.creativecommons.org/licencas/) - Permite distribuição e reprodução, desde que atribuam os devido créditos à publicação, ao autor(es) e que licenciem as novas criações sob termos idênticos. 
Resumen: Este documento propone ofrecer una síntesis de textos seleccionados de una gran encuesta publicada por Edições Câmara en 2017, sobre la condición de las personas negras en Brasil. Para este estúdio favorecemos el tema de la universidad en el contexto de las relaciones étnico-raciales.El estudio reunió una bibliografía amplia y diversa que sirvió de base para la revisión de la literatura y la construcción de uno de los ejes de un trabajo en progreso en el proyecto POLÍTICS - Política antirracismo en Europa y América Latina: producción de conocimiento, decisión política. y luchas colectivas. El estudio es oportuno para reflexionar y fundamentar un nuevo trabajo sobre el tema de las relaciones étnico-raciales en las sociedades contemporáneas, profundizar el conocimiento sobre la raza y el antirracismo, proporcionando una mayor comprensión de cómo las injusticias históricamente arraigadas están siendo cuestionadas por instituciones, en particular la universidad.

Palabras clave: Relaciones étnico-raciales. Universidad. Antirracismo 


\section{Introdução}

O presente trabalho oferece uma síntese de textos selecionados do "Relatório bibliográfico sobre a condição do negro no Brasil” (BRASIL, 2017), publicado pela Edições Câmara. Este amplo levantamento reúne uma bibliografia abrangente e diversificada sobre a condição do negro no Brasil, e serviu para alicerçar parte da revisão de literatura da construção de um dos eixos do projeto, em desenvolvimento, "POLITICS - A política de antirracismo na Europa e na América Latina: produção de conhecimento, decisão política e lutas coletivas" (Projeto 725402- POLITICS - ERC-2016-COG).

Tal projeto propõe aprofundar o conhecimento sobre o antirracismo, proporcionando uma maior compreensão sobre a forma como as injustiças historicamente enraizadas estão a ser questionadas por instituições e movimentos sociais de base, e tem dois objetivos principais: a análise de processos de produção de conhecimento sobre raça e antirracismo nas esferas da política governamental internacional, nacional, universidades públicas e movimentos sociais; a análise dos múltiplos caminhos de denúncia e mobilização coletiva contra o racismo quotidiano em relação às práticas policiais e às representações sobre antirracismo nos meios de comunicação social.

A revisão de literatura facilita o acesso de legisladores, pesquisadores e cidadãos em geral a um conjunto de textos importantes que discutem, analisam, e denunciam a condição da população negra ao longo da história do Brasil. Entende-se que o papel da pesquisa na elaboração e avaliação de políticas públicas possibilita instrumentalizar atores sociais, especialmente os alijados de posições vantajosas (negros, indígenas), entre outros, para participarem de negociações com o maior acervo de conhecimento possível. Configura-se, assim, pois, um compromisso ético e político da pesquisa.

Minha participação neste campo de estudos sobre relações étnico-raciais se deve a duas razões principais: primeiro, desde 2012, venho pesquisando o contexto da universidade, ensino superior/pós-graduação no Brasil (trajetórias de pesquisadores/as negros/as). Segundo, integro o projeto POLITICS, que procurará desvendar a configuração de diferentes noções de dignidade, justiça e igualdade resultantes das lutas antirracistas e das políticas públicas e a legislação recentes, que nos permitam pensar horizontes descoloniais. A pesquisa desafia as lacunas nos 
estudos comparativos que têm trabalhado a partir de abordagens meramente avaliativas, sustentando-se em contextos de pesquisa que permitem interrogar as relações entre os níveis global, nacional e local, nomeadamente as realidades das Nações Unidas, a Organização dos Estados Americanos (OAS), da União Europeia (UE) e das políticas públicas, universidades públicas e movimentos de base em quatro países: Brasil, Peru, Portugal e Espanha.

\section{Repertório bibliográfico sobre a condição do negro no Brasil: uma breve descrição}

A desigualdade social tem cor no Brasil e faz com que nossas políticas sociais, supostamente universais, terminem por obter resultados insuficientes, na medida em que não contribuem para a superação dessa ordem de desigualdade. Temos crescimento econômico, científico e tecnológico. Porém, as desigualdades sociais continuam sendo uma marca da sociedade brasileira. Por um lado, no cenário nacional, a partir dos direitos conquistados pela população negra com a promulgação da Constituição Federal de 1988 (BRASIL, 1988), e a aprovação da Lei $\mathrm{n}^{\circ}$ 12.288/2010 (BRASIL, 2010), representam um salto de qualidade no tratamento dado pelo Estado brasileiro à questão da igualdade racial. Por outro, denúncias de casos de racismo quase que diariamente nas redes sociais, imprensa, universidade, trabalho, além de produções institucionais, como a que constam no "Repertório bibliográfico sobre a condição do negro no Brasil” (BRASIL, 2017) que por nós mereceu uma análise mais detalhada.

A população negra se encontra em situação de desvantagem na sociedade em questões como saúde, moradia, saneamento básico, emprego e renda, encarceramento, educação (nosso objeto de análise), entre outras (PAIXÃO , 2010). O Atlas da violência: 2017, publicado pelo Instituto de Pesquisa Econômica Aplicada (IPEA), registra que "de cada 100 pessoas que sofrem homicídio no Brasil, 71 são negras” (CERQUEIRA, 2017, p.12).

Vale dizer que o Repertório (BRASIL, 2017) no qual se baseia este artigo, sobre a condição do negro no Brasil é resultado de uma parceria entre o Comitê Gestor do Programa PróEquidade de Gênero e Raça da Câmara dos Deputados e a Biblioteca da Câmara dos Deputados e foi organizado tendo como objetivos: facilitar o acesso da sociedade a textos de qualidade que discutem sob os ângulos mais variados a condição do negro no Brasil; oferecer instrumento de pesquisa confiável sobre a questão racial no Brasil; e organizar a informação para subsidiar a produção legislativa referente ao tema. 
O Repertório (BRASIL, 2017) definiu-se como recorte temporal da pesquisa o período de 1988 a 2016, incluindo publicações em $1^{\text {a }}$ edição ou edições subsequentes. A escolha do recorte temporal privilegiou o ano de 1988 como marco inicial por referência aos cem anos da abolição formal da escravidão; ano da promulgação da Constituição Federal vigente, (pelos avanços que esta significou em relação aos direitos e garantias da população negra). Quanto ao ano de 2016, foi por ser o ano anterior ao previsto para publicação dessa obra. Os critérios para a seleção dos trabalhos a que se propôs o Relatório (BRASIL, 2017) limitou-se a pesquisa apenas a textos sobre a condição do negro no Brasil disponibilizados on-line ou, se impressos, que estivessem disponíveis no acervo da Rede Virtual de Bibliotecas (RVBI). Outro critério, foram selecionados apenas textos escritos originalmente em português ou com tradução para o português, ainda que de autor estrangeiro. No que tange aos artigos de periódicos, observa-se que foram divididos em duas seções: eletrônicos e impressos.

No que se refere aos livros, apreende-se que foram referenciadas apenas obras impressas integrais ou capítulos específicos e existentes nas bibliotecas da Rede Virtual de Bibliotecas (RVIB). Além dos livros sobre o tema, o Repertório (BRASIL, 2017) dá destaque a outras produções: tese e dissertações, desse modo o Repertório solicitou ao Instituto Brasileiro de Informação em Ciência e Tecnologia (IBICT) uma pesquisa na base de dados da Biblioteca Digital Brasileira de Teses e Dissertações (BDTD), com os mesmos parâmetros de busca utilizados para os livros e artigos. Por sua vez, a categoria legislação, também fez parte do estudo, nesta direção foram realizadas pesquisas em duas coletâneas sobre o tema "Estatuto da igualdade racial e legislação correlata; e Legislação sobre comunidades quilombolas -, ambas da Edições Câmara, disponíveis na Biblioteca Digital da Câmara dos Deputados e também inseridas na parte Livros”. (BRASIL ,2017, p.16). Observa-se também, que as referências de legislação foram divididas em três seções, a saber: Constituição Federal, Decretos legislativos e leis, e Decretos.

As tendências dos textos selecionados estão relacionadas à discriminação racial do negro na sociedade brasileira, racismo estrutural e simbólico. Outros aspectos estão relacionados à saúde, segurança e educação, além de discutir sobre a condição da mulher negra, bem como a implementação do sistema de cotas nas universidades públicas no Brasil, isto é, sobre as políticas de ação afirmativa. Por fim, os autores do Repertório sublinham que, pela proposta estabelecida e 
pelo método adotado, "não se propõe a ser exaustivo nem se baseia em juízo de valor sobre o mérito dos textos referenciados" (BRASIL, 2017, p. 17).

\section{Metodologia}

Utiliza-se como metodologia para este estudo de revisão de literatura sobre a condição do negro na sociedade brasileira, pressupostos metodológicos baseados em Thompson (2011). Para o autor, esses pressupostos são aqueles que dizem respeito à forma como o conhecimento é construído. Thompson (2011) desenvolve um referencial metodológico que se fundamenta na hermenêutica de profundidade (HP) enquanto método para a investigação socio-histórica. Segundo o autor, a HP como referencial metodológico parte do suposto que o objeto sob análise é uma construção simbólica significativa que exige uma interpretação. Daí a importância da atenção ao processo de interpretação, posto que somente desse modo é possível fazer justiça ao caráter distintivo do campo-objeto, levando em consideração que as formas simbólicas estão também inseridas em contextos sociais e históricos de diferentes tipos e, como construções simbólicas significativas, estão estruturadas internamente de várias maneiras. As formas simbólicas são entendidas como ações, falas, imagens e textos recebidos, reproduzidos e colocados em circulação. No caso deste artigo, as formas simbólicas analisadas foram as referências indicadas no Repertório (BRASIL, 2017), contudo, privilegiamos as referências onde a questão da universidade, no contexto das relações étnico-raciais, foi apresentada. Isto é, buscamos sintetizar e explicar criativamente o que foi dito para chegar a possíveis significados.

\section{Seleção temática}

Realizamos um levantamento inicial do Repertório (BRASIL, 2017) e pudemos localizar, nas últimas décadas, um conjunto de estudos ${ }^{1}$ que problematizam a condição da população negra no Brasil.

\footnotetext{
${ }^{1}$ Vale dizer que estes estudos refletem parte da produção sobre a temática no Brasil, de acordo com os objetivos estabelecidos e pela metodologia adotada pelo citado Repertório.
} 
SILVA, Marcos Antonio Batista da. Pesquisas contemporâneas sobre a condição do negro no Brasil e a universidade: tendências e debates (1988-2016).

Tabela 1 - Produção acadêmica brasileira referente a população negra no Brasil (1988-2016)

\begin{tabular}{l|l|l|l}
\hline \multicolumn{2}{c|}{ Produção Acadêmica } & \multicolumn{2}{|c}{ Total } \\
\hline \multirow{2}{*}{ Artigos de periódicos } & Eletrônicos & 283 & 372 \\
\cline { 2 - 3 } & Impressos & 89 & \\
\hline \multirow{2}{*}{ Livros } & Integrais & 360 & 489 \\
\cline { 2 - 3 } & Capítulos & 129 & \\
\hline \multirow{2}{*}{ Teses e dissertações } & Teses & 188 & \multirow{2}{*}{803} \\
\cline { 2 - 3 } & Dissertações & 615 & \\
\hline \multirow{2}{*}{ Legislação } & Constituição Federal & 1 & \\
\cline { 2 - 3 } & Decretos Legislativos e Leis & 11 & \\
\cline { 2 - 3 } & Decretos & 7 & \\
\hline Total & & & \\
\hline
\end{tabular}

Nota: Elaborado pelo autor.

Fonte: BRASIL. Repertório bibliográfico sobre a condição do negro no Brasil. [recurso eletrônico]. Brasília: Edições Câmara, 2017. Disponível em: http://bd.camara.gov.br/bd/handle/bdcamara/34741. Acesso em: 4 abr. 2018.

Ressalta-se que este artigo, pelos objetivos estabelecidos e pela metodologia adotada, não se propõe a ser exaustivo, isto é, para este trabalho, para além dos conteúdos já explicitados neste texto, realizamos um levantamento inicial e parcial envolvendo um dos eixos do projeto em desenvolvimento, ou seja, pensar racismo no ensino superior e cultura acadêmcia.

Nesta direção analisamos a produção acadêmica que consta do Repertório (BRASIL, 2017) :artigos, livros , teses e dissertações, legislação, cujo o título da produção estivesse relacionado com está temática orientada pelos descritores, a saber: "ensino superior"; "educação superior"; "estudantes universitários"; "professora(es) universitária(os)"; "universidade"; "universitários"; "cultura acadêmica".

Primeira parte: artigos de periódicos (impressos e eletrônicos).

Desse modo, na primeira parte, artigos de periódicos foram localizados dezoito artigos (18) publicados entre 2004 e 2015, relacionados com os descritores por nós proposto e acima citados como mostra a tabela 2 . 
SILVA, Marcos Antonio Batista da. Pesquisas contemporâneas sobre a condição do negro no Brasil e a universidade: tendências e debates (1988-2016).

Tabela 2 - Quantidade de artigos publicados por anos e periódico (Relatório,2017)

\begin{tabular}{c|c|l}
\hline $\begin{array}{c}\text { Ano de } \\
\text { publicação }\end{array}$ & $\begin{array}{c}\text { Quantidade de } \\
\text { pulicação/ano }\end{array}$ & \multicolumn{1}{c}{ Periódico } \\
\hline 2004 & 2 & $\begin{array}{l}\text { Revista Brasileira de Educação, Rio de Janeiro. } \\
\text { Estudos Avançados, São Paulo. }\end{array}$ \\
\hline 2006 & 2 & $\begin{array}{l}\text { Educar em Revista, Curitiba. } \\
\text { Cadernos de Pesquisa, São Paulo. }\end{array}$ \\
\hline 2007 & 1 & Revista Brasileira de Educação, Rio de Janeiro. \\
\hline 2008 & 2 & $\begin{array}{l}\text { Cadernos Pagu, Campinas. } \\
\text { Revista Estudos Feministas, Florianópolis. }\end{array}$ \\
\hline 2010 & 2 & $\begin{array}{l}\text { Psico-USF, Bragança Paulista. } \\
\text { Cadernos de Pesquisa, São Paulo. }\end{array}$ \\
\hline 2013 & 1 & $\begin{array}{l}\text { Revista Brasileira de Estudos de População, São Paulo. } \\
\text { Revista da Avaliação da Educação Superior, Campinas. }\end{array}$ \\
\hline 2014 & 3 & $\begin{array}{l}\text { Cadernos de Pesquisa, São Paulo. } \\
\text { Psicologia \& Sociedade, Florianópolis. } \\
\text { Universitas Humanística, Bogotá. } \\
\text { Revista Brasileira de Educação, Rio de Janeiro. }\end{array}$ \\
\hline \multirow{2}{*}{3015} & $\begin{array}{l}\text { Cadernos de Pesquisa, São Paulo. } \\
\text { Revista Brasileira de Ciência Política, Brasília. } \\
\text { Educação em Revista, Belo Horizonte. }\end{array}$ \\
\hline
\end{tabular}

Nota: Elaborado pelo autor.

Fonte: BRASIL. Repertório bibliográfico sobre a condição do negro no Brasil. [recurso eletrônico]. Brasília: Edições Câmara, 2017. Disponível em: http://bd.camara.gov.br/bd/handle/bdcamara/34741. Acesso em: 4 abr. 2018.

Observa-se que importantes periódicos brasileiros publicaram textos de autores que têm se destacado no campo, tais como: Barreto (2015), Camino et al. (2014), Daflon e Feres Júnior; Campos (2013), Lima et al. (2014), Passos (2015), entre outros. Esses autores discutiram e analisaram o tema das políticas de ação afirmativa na sociedade brasileira, que foi abordado de forma direta ou indireta, como subsídio para a investigação de outros objetos de pesquisas, configurando assim uma ampla variedade de subtemas.

Ações afirmativas são medidas especiais e temporárias, tomadas pelo Estado e/ou pela iniciativa privada, espontânea ou compulsoriamente, com o objetivo de eliminar desigualdades historicamente acumuladas, garantindo a igualdade de oportunidade e tratamento, bem como de compensar perdas provocadas pela discriminação e marginalização, por motivos raciais, étnicos, religiosos, de gênero e outros (BRASIL, 1996, p. 10).

No discurso acadêmico desse conjunto, de forma geral, as cotas são entendidas como uma ação afirmativa em prol da garantia do respeito à diversidade racial e da superação das desigualdades historicamente construídas. Pudemos observar também que os artigos que 
constam do Repertório (BRASIL, 2017) e relacionados com os descritores por nós selecionados, apontaram outras tendências, a saber: ingresso de negros a ensino superior brasileiro, trajetórias universitárias, cultura acadêmica.

No segundo conjunto de textos, agrupamos os estudos que abordam o tema do ingresso de negros no ensino superior brasileiro a partir de questões de classe, raça e escolarização (ARTES e RICOLDI, 2015; OSÓRIO, 2009). Por exemplo, Artes e Ricoldi (2015) dão destaque à presença reduzida de negros no ensino superior no Brasil e investigam se, e de que forma, as mudanças observadas no perfil dos estudantes de graduação se alteraram nos últimos anos, isto é, entre 2000 e 2010. As autoras indicam em suas análises uma melhora nas taxas de acesso à graduação para os negros, devido a políticas de ação afirmativa no ensino superior público, porém com resultados ainda distantes de sua participação no total da população brasileira. Vale ressaltar que Censo Demográfico do ano de 2010 (BRASIL, 2010), realizado pelo Instituto Brasileiro de Geografia e Estatística - IBGE (2010) - órgão do governo brasileiro que produz estatísticas nacionais -, indicou que foi a primeira vez em que o número de pessoas autodeclaradas negras (pretas + pardos) supera a população branca. Este é um fato importante, porque reflete no ingresso de negros ao ensino superior no Brasil e sugere uma mobilidade educacional atualmente provocada em parte pelas políticas de ação afirmativa com recorte racial na graduação.

No terceiro conjunto de textos, temos aqueles preocupados com as trajetórias de negros no ensino superior, nesta direção, Crisostomo e Reigota (2010) assinalam que neste nível de ensino, a condição da mulher negra como professora universitária é a de exclusão e que ainda que em se tratando de representações específicas, o modo como a questão racial se apresenta na universidade não se afasta da realidade de outros segmentos da sociedade. Por sua vez, Passos (2015) chama a atenção para a importância de se discutir os desafios e tensionamentos que a implantação das ações afirmativas trouxeram ao cotidiano da universidade, visando assegurar o acesso e a permanência, com qualidade social, a esta população universitária (estudantes cotistas negros).

\section{Segunda parte: livros (integrais e capítulos)}

Na segunda parte livros analisamos a produção acadêmica que consta do Repertório (BRASIL, 2017) cujo o título da produção estivesse orientada pelos descritores, a saber: "ensino 
superior"; "educação superior"; "universidade", assim foram encontrados quinze (15) trabalhos. Nesta direção, pudemos apreender que os livros (integrais e capítulos) que contam do Repertório (BRASIL, 2017) apontam três (3) tendências, a saber: ações afirmativas no ensino superior brasileiro para negros, diversidade étnica-racial, identidade e trajetórias. O primeiro especto, de modo geral, diz respeito às políticas de ações afirmativas, porém, evocando discussões jurídicas e constitucionais, não constantes nos artigos já referenciados neste estudo, como por exemplo, os estudos de: Bertúlio, Duarte e Silva (2008), Lewandowski (2013).

Entende-se que a questão das cotas raciais no Brasil foi alvo de um acirrado debate de argumentos teóricos e ideológicos, e buscou-se consolidar uma nova cultura, de modo a transformar a visão geral da forma de ver a população negra no país. A visibilidade que as cotas proporcionaram à população negra ressaltou a importância dos debates para criação de tais medidas. Ao apreciar a questão da validade das cotas raciais para ingresso no ensino superior, o Supremo Tribunal Federal (STF) destacou o papel integrador da universidade e da sociedade ao exigir a adoção de medidas de equidade.

O segundo aspecto se refere à diversidade étnica. Syss (2008) contribuiu para esta discussão na educação superior brasileira ao analisar no que se refere à educação das relações étnico-raciais na escola e na sociedade. Syss (2008) apresenta um pouco da história da desigualdade e do preconceito racial no Brasil, além de mostrar o que os Núcleos de Estudos Afro-Brasileiros e Indígenas (NEABs) e algumas universidades públicas estão a fazer para superar obstáculos em suas experiências de intervenções, visando à construção de alternativas de intervenção pedagógica no processo educativo no que tange à educação para as relações étnicoraciais.

\section{Terceira parte: teses e dissertações}

Com efeito, no que se refere ao terceiro aspecto, identidade e trajetórias, o livro de Teixeira (2003) "Negros na universidade: identidade e trajetórias de ascensão social no Rio de Janeiro" mereceu por nós uma análise mais apurada, pelo fato do locus da pesquisa da autora ser um dos locais onde será também desenvolvido um dos eixos do projeto já mencionado neste estudo (universidade) e pelo campo de estudo. Apreendemos que o livro é originário da tese "Negros em ascensão social: trajetórias de alunos e professores universitários no Rio de Janeiro", 
defendida em 1998 pela autora, em Antropologia Social, pelo Museu Nacional/da Universidade Federal do Rio de Janeiro(UFRJ).

O objetivo foi identificar e compreender as estratégias que possibilitaram que negros (professores e alunos) tivessem sucesso onde a grande maioria "fracassa", ou onde nem mesmo tem a possibilidade de chegar, isto é, a universidade. O resultado é uma análise provocativa. Teixeira (2003, s/p) lembra que, no Brasil, o número de estudantes negros que chegam à universidade é tão reduzido que o senso comum os toma como a exceção que confirma a regra e questiona: "seriam esses estudantes mesmo a exceção? Ou seriam esse alunos e professores o resultado de trajetórias de vidas cheias de percalços e de lutas?”.

A autora frisa que os alunos e professores negros se concentram nas carreiras de menor retorno financeiro após a diplomação. O contrário, por sua vez, ocorre com os alunos e professores brancos. De fato, a pesquisa realizada mostra também, que os negros estão em maior número nos cursos de Ciências Humanas e Sociais, logo depois, na área Tecnológica e, por último, na área Biomédica. Discutiu-se também, sobre os projetos e as trajetórias de ascensão social dos entrevistados. Para a autora, o elemento fundamental que explica as trajetórias de sucesso investigadas se encontra na possibilidade de formação de uma rede de solidariedade e ajuda (pessoas, família, instituições, grupos etc.), que acaba por proporcionar o apoio à superação de dificuldades relacionadas à condição socioeconômica e aos processos de discriminação racial.

$\mathrm{Na}$ terceira parte analisamos a categoria de teses e dissertações que constam do Repertório (BRASIL, 2017). Nas últimas décadas, o Estado brasileiro vem se movimentando no sentido de atender antigas demandas dos movimentos sociais. Exemplo disso são as ações específicas, direcionadas à camada da população (negros, indígenas), que, em virtude de suas origens étnicoraciais, vivencia privações de diversas naturezas. Nesse sentido, o Estado vem implementando políticas públicas com vistas à superação das desigualdades étnico-raciais no país. As medidas se justificam pela extensa e periódica divulgação de indicadores socioeconômicos, sob responsabilidade de Instituições de estatística e de pesquisa como o Instituto Brasileiro de Geografia e Estatística (IBGE), o Instituto de Pesquisa Econômica Aplicada (IPEA) mostra que grandes diferenciais raciais marcam praticamente todos os campos da vida social brasileira.

Nesta direção, apreende-se nesta terceira parte que os estudos sobre ações afirmativas contemplam grande parte das produções acadêmicas por nós investigadas. Trata-se de um campo 
em expansão no Brasil e atestado pelos indicadores de produção acadêmica: número de teses e dissertações defendidas e número de publicações já indicados neste texto. Assim, no âmbito deste artigo, realizamos um levantamento na base do Repertório (BRASIL, 2017) e com os descritores "ensino superior"; "educação superior"; "universidade”, "cultura acadêmica", "pesquisadores negros", "graduação", "universitários/as", "cursos superiores", que nos permitiram observar uma produção de 62 trabalhos (15 teses e 47 dissertações).

Gráfico 1 - Evolução da produção científica de 2000 a 2016 (teses e dissertações)

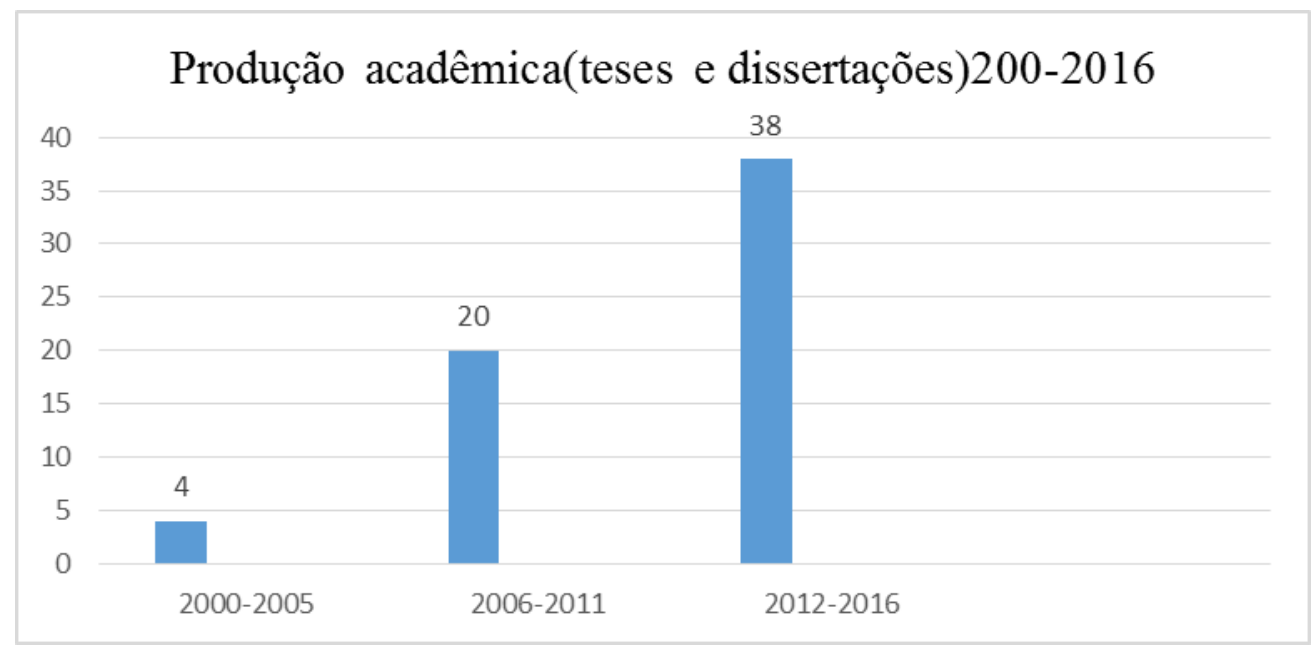

Nota: Elaborado pelo autor.

Fonte: BRASIL. Repertório bibliográfico sobre a condição do negro no Brasil. [recurso eletrônico]. Brasília: Edições Câmara, 2017. Disponível em: http://bd.camara.gov.br/bd/handle/bdcamara/34741. Acesso em: 4 abr. 2018.

Observa-se pelo gráfico o número crescente de produções brasileiras a partir dos anos 2000, concentrados principalmente entre 2012 e 2016 com 38 estudos. Ressalta-se também que a maioria desses trabalhos foram concentrados na área de Educação (34), seguidos pelas áreas de Ciências Sociais e Psicologia (7) estudos cada, e Direito (6). Outras áreas também se fizeram presentes: Política Social (4), Enfermagem (2), Serviço Social (2), Linguística (1) e Mudança Social e Participação Política (1). Nota-se que a grande maioria das produções se concentrou na área de humanidades.

Esta parte incluiu a produção científica (teses e dissertações), que enfatizou de forma direta ou indireta como subsídio para a investigação de outros objetos de pesquisas, configurando assim uma ampla variedade de subtemas. No discurso acadêmico desse conjunto, de forma geral, 
encontramos trabalhos sobre identidade, discriminação e saúde mental (SANTOS JÚNIOR, 2011), estudantes africanos (CABRAL, 2015), trajetórias universitárias (SILVA, 2016), prática de inclusão(PEREIRA, 2011), cultura acadêmica (GRISA, 2015).

Outros autores apontaram uma tendência dessa produção acadêmica, os estudos sobre políticas de ações afirmativas ${ }^{2}$ são exemplos: Santos (2014), Fonseca (2014), Goto (2014), Lima (2014), Lopes (2014), Melo (2016), entre outros. Isto é, destacam-se temas que estão proporcionando especial embasamento teórico para pesquisa em andamento junto ao projeto POLITICS, já evidenciado neste texto, pelo enfoque teórico encontrado sobre relações étnicoraciais e seu campo de estudos.

Entende-se que a profusão de discursos e práticas sobre ação afirmativa com recorte racial do Brasil do segundo milênio criou sustentação para novos temas para a pesquisa acadêmica, que também passa a contribuir para difusão desses discursos e práticas fora dos muros universitários, mas também propor pensar a ação afirmativa como uma das estratégias, mas não a única de combate à desigualdade racial brasileira.

Para além das ações afirmativas, observam-se outras tendências como acima mencionadas. Nesta direção, de autores que pesquisaram sobre trajetórias universitária de negros, Silva (2016) entende que a dinâmica social resulta em um jogo complexo de desigualdades em diferentes esferas, econômica, política, cultural, educacional, e nos diversos cenários nos quais estão inseridos a população negra no país e assinala que em suas trajetórias de vida e educacionais, os atores sociais pesquisados, historicamente ativos, encontraram barreiras, impostas pela sociedade, para a realização de seus projetos de vida adulta, dentro e fora dos muros da universidade em suas práticas de inclusão social, bem como apontou Pinheiro (2011).

Outros estudos expõe a discriminação racial do negro na sociedade brasileira e o racismo estrutural, no que tange, em particular, ao sistema educacional e ao contexto da saúde da população negra universitária, como aponta o estudo de Santos Júnior (2011).

Queixas indicativas de sofrimento psíquico, com predomínio de sintomas depressivos ou ansiosos, originário da discriminação racial aparecem em pesquisas, como por exemplo a de foram frequentes, principalmente entre as mulheres [...]. As experiências discriminatórias mais relatadas foram contra a aparência física e o nível socioeconômico (SANTOS JÚNIOR, 2011, p. 209-2010).

\footnotetext{
${ }^{2}$ Ver o Decreto $\mathrm{n}^{\mathrm{o}} 7.824$, de 11 de outubro de 2012 regulamenta a Lei ${ }^{\circ} 12.711$, de 29 de agosto de 2012, que dispõe sobre o ingresso nas universidades federais e nas instituições federais de ensino técnico de nível médio.
} 
Nessa direção, sobre uma das questões apontadas por Santos Júnior (2011), a questão de gênero, em particular, da mulher negra, encontramos na literatura investigada outros autores que discutem esta temática, Guedes (2012), Machado (2011), Natel (2014), Von Dentz (2016), entre outros. De mo do geral, essas dissertações buscaram compreender quais os percursos, apoios e barreiras vivenciados por esta população no espaço universitário e como as questões de gênero, raça e classe interferem na prática.

Estudos como os de Artes (2017) e Silva (2016) problematizam o ingresso de estudantes negros em cursos de graduação e pós-graduação em determinadas áreas - Educação, Ciências Humanas e Sociais, entre outras. Há toda uma área para explorar, pensando na temática das relações étnico-raciais, de não acesso aos cursos de "maior prestígio". Isso é, prestígio pode ser associado à relação candidato-vaga no processo seletivo, ao potencial de ganho na carreira, ou à hierarquia social das profissões.

O predomínio de mulheres nas formações em nível superior está posto na literatura brasileira desde os anos de 1980. Uma análise que considere as diferentes áreas de inserção por sexo indica uma concentração das mulheres nas formações de menor prestígio, ligadas ao cuidado e à área da educação. A partir de dados do Censo da Educação Superior, em especial no período de 2010 a 2015, os resultados descritos apresentam o perfil das mulheres nas Instituições de Educação Superior no Brasil, na interface com cor/raça e indicam uma maior presença nas áreas de Educação e Saúde (de menor prestígio social) e uma ampliação, ainda pontual, nas áreas das Ciências Exatas e Engenharias (de maior prestígio social). Outros aspectos indicam uma maior presença em cursos de EAD e em IES privadas. Discutir e dimensionar, quantitativamente, a ocupação dos espaços acadêmicos por sexo e as hierarquias entre cursos é essencial para problematizar que apesar das mulheres serem maioria no ensino superior brasileiro, a esperada equidade na ocupação dos espaços acadêmicos é ainda um grande desafio (ARTES, 2017).

Esses estudos indicam que a dinâmica social resulta em um jogo complexo de desigualdades em diferentes esferas, econômica, política e cultural, e nos diversos cenários nos quais estão inseridos a população negra no país. Aqui, a universidade foi entendida como locus de objetivação e de apropriação do conhecimento, por um lado, "suficiente" para propiciar aos professores, pesquisadores negros e alunos negros a mobilidade social e a consciência das desigualdades raciais e, por outro lado, apresentando-se também como lugar de desigualdades raciais, de situações de preconceitos e discriminações. Um exemplo disso é o que assinala Cabral (2015) em seu estudo ao investigar sobre o Programa de Estudantes Convênio de Graduação (PEC-G) como política de acesso ao ensino superior para os estudantes africanos nas Instituições 
de Ensino Superior (IES) brasileiras, desse modo, uma das considerações do autor, diz respeito ao fenômeno do preconceito e da discriminação racial, elemento desconhecido no país de origem, e que acaba sendo uma das barreiras encontradas por estes jovens ao ingressarem no Brasil.

Merece destaque também, a dissertação de Passos (2006), que examinou a contribuição de três Núcleos de pesquisa de universidades do Rio de Janeiro para o enfrentamento do racismo no Brasil. Conhecidos como Núcleos de Estudos Afro-Brasileiros (NEABs), o autor sublinha que os NEABs representam uma instância acadêmica de construção de conhecimento coletivo e interdisciplinar sobre a população negra e articulam os múltiplos discursos sobre as relações raciais que existem na academia, promovendo, por meio de suas atividades e publicações, a concretização desses discursos e por serem espaços de construção de produção no que diz respeito às questões étnico-raciais.

\section{Quarta parte: legislação}

Na quara parte legislação analisamos a produção que consta do Repertório (BRASIL, 2017), no contexto do ensino superior. Entende-se que as políticas públicas formuladas pelo Estado brasileiro para a educação superior por meio de instrumentos normativos têm como marco a Constituição Federal de 1988 (BRASIL, 1988). Parte-se do princípio de que tais políticas têm sido materializadas a partir do ordenamento jurídico. Neste sentido, buscamos situar no presente estudo que nosso ponto de partida é a Constituição Federal, por ser a lei máxima de nosso país. Assim, valendo-se do uso dos descritores "cor/raça"; "racismo"; "ensino superior", "universidade(s)", captamos, descrevemos e analisamos esses itens que constavam do Repertório (BRASIL, 2017). A primeira análise recai sobre a Constituição Federal de 1988 (BRASIL,1988), onde localizamos:

TÍTULO I - Dos Princípios Fundamentais [...]. Art. 3o Constituem objetivos fundamentais da República Federativa do Brasil: I-construir uma sociedade livre, justa e solidária; II-garantir o desenvolvimento nacional; III-erradicar a pobreza e a marginalização e reduzir as desigualdades sociais e regionais; IV-promover o bem de todos, sem preconceitos de origem, raça, sexo, cor, idade e quaisquer outras formas de discriminação (BRASIL, 1988, p.11, grifo do autor)

No que se refere ao "TÍTULO II DOS DIREITOS E GARANTIAS FUNDAMENTAIS CAPÍTULO I DOS DIREITOS E DEVERES INDIVIDUAIS E COLETIVOS [...] XLII - a 
prática do racismo constitui crime inafiançável e imprescritível, sujeito à pena de reclusão, nos termos da lei” (BRASIL, 1988, p.15, grifo do autor). De forma que só encontramos tais referências sobre a questão étnico-racial na Constituição Federal de 1988. No que tange ao Capítulo III da Educação, da Cultura e do Desporto, seção I da Educação, identificamos:

Art. 207. As universidades gozam de autonomia didático-científica, administrativa e de gestão financeira e patrimonial, e obedecerão ao princípio de indissociabilidade entre ensino, pesquisa e extensão. $\S 1^{\circ}$ É facultado às universidades admitir professores, técnicos e cientistas estrangeiros, na forma da lei. ...§ $2^{\circ}$ As atividades de pesquisa, de extensão e de estímulo e fomento à inovação realizadas por universidades e/ou por instituições de educação profissional e tecnológica poderão receber apoio financeiro do Poder Público (BRASIL, 1988, p.123.grifo do autor).

Além a relacionada a Atos das Disposições Constitucionais Transitórias:

Art. 29. Enquanto não aprovadas as leis complementares relativas ao Ministério Público e à Advocacia-Geral da União, o Ministério Público Federal, a Procuradoria-Geral da Fazenda Nacional, as Consultorias Jurídicas dos Ministérios, as Procuradorias e Departamentos Jurídicos de autarquias federais com representação própria e os membros das Procuradorias das Universidades fundacionais públicas continuarão a exercer suas atividades na área das respectivas atribuições (BRASIL, 1988, p.148. grifo do autor).

No que se refere à universidade, em conexão com as relações étnico-raciais, não encontramos nenhum registro que fizesse menção à questão. Na sequência dessa discussão apresentamos a seção sobre Decretos Legislativos (3), Leis (8) e Decretos (7), no que concerne à questão étnico-racial e à universidade, localizamos a Lei no 12.711, de 29 de agosto de 2012 (Lei de Cotas de Ingresso nas Universidades), que dispõe sobre o ingresso nas universidades federais e nas instituições federais de ensino técnico de nível médio e dá outras providências (BRASIL, 2012), que por nós mereceu uma análise mais apurada, por ser a categoria que atendeu um dos descritores propostos por este artigo, "universidade(s)".

Nesta direção, destaca-se também que o Decreto $n^{\circ} 7.824$, de 11 de outubro de 2012 (BRASIL, 2012), regulamenta a Lei acima supracitada, que dispões sobre o ingresso nas universidades federais e nas instituições federais de ensino técnico de nível médio, bem como, destacamos, a legislação sobre a reserva de cotas para candidatos negros no serviço público federal, que foi estabelecida pela Lei $n^{\circ}$ 12.990/2014 (BRASIL, 2014), que já se encontra em vigor desde sua publicação. A verificação das informações prestadas pelos candidatos cotistas ainda não estava padronizada, o que gerava contestações. 
Desse modo, a Orientação ${ }^{3}$ Normativa $n^{\circ} 4$ de abril de 2018 (BRASIL, 2018) determina a verificação da veracidade da autodeclaração do candidato que se denominar preto ou pardo(negro) para concorrer pelo sistema de cotas. Esse procedimento deverá ser realizado antes da publicação da homologação do resultado final do concurso. $\mathrm{O}$ edital do concurso deverá prever o momento em que a verificação será realizada. Desse modo, o candidato somente será confirmado como negro (preto ou pardo) por meio de verificação presencial.

Para a realização da verificação, os órgãos deverão instituir uma comissão especial, composta por membros distribuídos por gênero, cor e, preferencialmente, naturalidade.

\begin{abstract}
Art. $6^{\circ} \mathrm{O}$ procedimento de heteroidentificação será realizado por comissão criada especificamente para este fim. $\S 1^{\circ}$ A comissão de heteroidentificação será constituída por cidadãos: I - de reputação ilibada; II - residentes no Brasil; III - que tenham participado de oficina sobre a temática da promoção da igualdade racial e do enfrentamento ao racismo com base em conteúdo disponibilizado pelo órgão responsável pela promoção da igualdade étnica previsto no $\S 1^{\circ}$ do art. 49 da Lei $n^{\circ} 12.288$, de 20 de julho de 2010; e IV - preferencialmente experientes na temática da promoção da igualdade racial e do enfrentamento ao racismo. $\S 2^{\circ}$ A comissão de heteroidentificação será composta por cinco membros e seus suplentes (BRASIL, 2018).
\end{abstract}

Entende-se que se trata de uma medida que busca direcionar as políticas públicas aos que realmente têm direito a ela.

\title{
Considerações finais
}

A partir da denúncia do mito da democracia, especialmente na década de 1970, o país testemunhou uma ampla mobilização em torno da questão racial, com destaque às diversas entidades dos movimentos sociais negros, trazendo o tema de volta à arena política, fazendo com que os governantes, que até então não tinham demonstrado atenção, se atentassem aos problemas das desigualdades raciais. Ao longo das últimas décadas, o Estado brasileiro tem adotado medidas que visam superar as desigualdades raciais, dando maior ênfase àquelas que dizem respeito às políticas educacionais, porém assinala-se que, ao mesmo tempo em que tais políticas

\footnotetext{
3 Ver: Ministério do Planejamento, Desenvolvimento e Gestão Secretaria de Gestão de Pessoas. PORTARIA NORMATIVA N ${ }^{\circ}$ 4, DE 6 DE ABRIL DE 2018. Regulamenta o procedimento de heteroidentificação complementar à autodeclaração dos candidatos negros, para fins de preenchimento das vagas reservadas nos concursos públicos federais, nos termos da Lei $n^{\circ} 12.990$, de 9 de junho de 2014.
} 
são fundamentais para a superação de desigualdades, elas só se efetivam pela ação e força dos sujeitos e dos movimentos sociais.

Desse modo, este artigo se propôs pela (re)leitura do "Repertório bibliográfico sobre a condição do negro no Brasil” (BRASIL, 2017), privilegiar a produção científica (artigos, dissertações e teses, capítulos de livros, livros e legislações), para pensar em primeiro lugar o racismo no ensino superior brasileiro. A síntese dos estudos captados e analisados (cujo descritor do título do trabalho estava relacionado à universidade) vem reforçar a necessidade da sequência de implementações de políticas de ação afirmativas para a população negra no país. Políticas essas que possam garantir uma maior equidade de oportunidades que alterem a situação de desigualdade e possibilitem a inclusão da população negra nos segmentos mais dinâmicos no sistema educacional, em especial no ensino superior. Considera-se fundamental atingir mudanças nas representações culturais e na inclusão das populações racializadas: população negra, indígena, como indicam as Leis 10.639/2003 e 11.645/2008, como um domínio institucional onde as desigualdades e os quadros eurocêntricos foram historicamente reproduzidos e legitimados.

Políticas de ação afirmativa são essenciais em setores da vida social brasileira, bem como para alguns segmentos sociais, especialmente os alijados de posições vantajosas, para participarem de negociações com o maior acervo de conhecimento possível, em especial negros, e indígenas. Apesar de todos os avanços nos campos social, legal e institucional em relação à promoção da igualdade racial, acredita-se que este trabalho possa ser uma contribuição oportuna para ampliar a discussão e reflexão da promoção da igualdade racial, reforçando o compromisso com a promoção da igualdade racial no país.

Diante desse cenário algumas questões poderiam orientar futuros estudos no campo do ensino superior e relações étnico-raciais: de que modos os sistemas educativos têm respondido às exigências dos movimentos sociais? Há rupturas e/ou continuidades de lógicas eurocêntricas que sustentam o racismo na universidade? As práticas educacionais, como a construção do currículo, têm procurado desafiar o paradigma eurocêntrico através das diferenças representadas pelas experiências históricas de negros e indígenas? 
SILVA, Marcos Antonio Batista da. Pesquisas contemporâneas sobre a condição do negro no Brasil e a universidade: tendências e debates (1988-2016).

\section{Referências}

ARTES, Amélia. A presença de mulheres no ensino superior brasileiro: uma maioria sem prestígio. In: SEMINÁRIO INTERNACIONAL FAZENDO GÊNERO, 11.; WOMEN'S WORLDS CONGRESS, 13. 2017, Florianópolis. Anais [...]. Florianópolis, SC: 2017, ISSN 2179-510X. Disponível em: http://www.en.wwc2017.eventos.dype.com.br/resources/anais/1496748817_ARQUIVO_fazendogenero final.pdf. Acesso em: 10 abr. 2018.

ARTES, Amélia; RICOLDI, Arlene Martinez. Acesso de negros no ensino superior: o que mudou entre 2000 e 2010. Cadernos de Pesquisa, São Paulo, v. 45, n. 158, p. 858-881, dez. 2015. Disponível em: http://www.scielo.br/scielo.php?pid=S0100-15742015000400858\&script=sci_abstract\&tlng=pt. Acesso em: 10 abr. 2018.

BARRETO, Paula Cristina da Silva. Gênero, raça, desigualdades e políticas de ação afirmativa no ensino superior. Revista Brasileira de Ciência Política, Brasília, n. 16, p. 39-64, abr. 2015. Disponível em: http://www.scielo.br/pdf/rbcpol/n16/0103-3352-rbcpol-16-00039.pdf. Acesso em: 4 abr. 2018.

BERTÚLIO, Dora Lúcia de Lima; DUARTE, Evandro C. Piza; SILVA, Paulo Vinícius Baptista (coord.). Cotas raciais no ensino superior: entre o jurídico e o político. Curitiba: Juruá, 2008.

BRASIL. Constituição da República Federativa do Brasil de 1988. Brasília: Câmara dos Deputados, 1988. Disponível em: https://www2.senado.leg.br/bdsf/handle/id/518231. Acesso em: 4 abr. 2018.

BRASIL. Decreto $\mathbf{n}^{\mathbf{0}} \mathbf{7 . 8 2 4}$, de 11 de outubro de 2012. Regulamenta a Lei $\mathrm{n}^{\circ} 12.711$, de 29 de agosto de 2012, que dispõe sobre o ingresso nas universidades federais e nas instituições federais de ensino técnico de nível médio. Brasília: Congresso Nacional, 2012a. Disponível em: http://www.planalto.gov.br/ccivil_03/_ato2011-2014/2012/decreto/D7824.htm. Acesso em: 4 abr. 2018.

BRASIL. Lei 12.990, de 9 de junho de 2014. Reserva aos negros $20 \%$ (vinte por cento) das vagas oferecidas nos concursos públicos para provimento de cargos efetivos e empregos públicos no âmbito da administração pública federal, das autarquias, das fundações públicas, das empresas públicas e das sociedades de economia mista controladas pela União. Brasília: Congresso Nacional, 2014. Disponível em: http://www.planalto.gov.br/ccivil_03/_ato2011-2014/2014/lei/112990.htm. Acesso em: 4 abr. 2018.

BRASIL. Lei no 10.639, de 9 de janeiro de 2003. Brasília: MEC, 2003. Disponível em: http://etnicoracial.mec.gov.br/images/pdf/lei_10639_09012003.pdf . Acesso em: 8 mar. 2018.

BRASIL. Lei no 11.645, de 10 de março de 2008. Disponível em: http://pfdc.pgr.mpf.mp.br/atuacao-econteudos-de-apoio/legislacao/educacao/Lei_n_11.645-2008_altera_lei_Hist_Africa.pdf. Acesso em: 8 mar. 2018.

BRASIL. Lei no 12.288, de 20 de julho de 2010. Estatuto da Igualdade Racial. Brasília: Câmara dos Deputados, 2010. Disponível em: http://www2.camara.leg.br/legin/fed/lei/2010/lei-12288-20-julho-2010607324-norma-pl.html. Acesso em: 4 mar. 2018.

BRASIL. Lei $\mathbf{n}^{\circ}$ 12.711, de 29 de agosto de 2012. Dispõe sobre o ingresso nas universidades federais e nas instituições federais de ensino técnico de nível médio e dá outras providências. Brasília, 2012b. Disponível em: https://www2.camara.leg.br/legin/fed/lei/2012/lei-12711-29-agosto-2012-774113normaatualizada-pl.pdf. Acesso em: 8 mar. 2018.

BRASIL. CÂMARA DOS DEPUTADOS. Repertório bibliográfico sobre a condição do negro no Brasil. [recurso eletrônico. Brasília: Edições Câmara, 2017. Disponível em: http://bd.camara.gov.br/bd/handle/bdcamara/34741. Acesso em: 4 abr. 2018. 
SILVA, Marcos Antonio Batista da. Pesquisas contemporâneas sobre a condição do negro no Brasil e a universidade: tendências e debates (1988-2016).

BRASIL. MINISTÉRIO DA JUSTIÇA. SECRETARIA DE ESTADO DOS DIREITOS HUMANOS. Relatório do grupo de trabalho interministerial população negra. Brasília: MJ/SEDH, 1996.

BRASIL. MINISTÉRIO DO PLANEJAMENTO, DESENVOLVIMENTO E GESTÃO. SECRETARIA DE GESTÃO DE PESSOAS. Portaria Normativa no 4, de 6, de abril, de 2018. Regulamenta o procedimento de heteroidentificação complementar à autodeclaração dos candidatos negros, para fins de preenchimento das vagas reservadas nos concursos públicos federais, nos termos da Lei ${ }^{\circ} 12.990$, de 9 de junho de 2014. Disponível em: https://www.mdh.gov.br/biblioteca/igualdade-racial/portaria-normativano-4-2018-regulamenta-o-procedimento-de-heteroidentificacao-complementar-a-autodeclaracao-doscandidatos-negros-em-concursos-publicos/view. Acesso em: 8 mar. 2018.

CABRAL, Frederico Matos Alves. Os estudantes africanos nas Instituições de Ensino Superior brasileiras: o Programa de Estudante Convênio de Graduação (PEC-G). 2015. 203p. Dissertação (Mestrado em Sociologia) - Instituto de Filosofia e Ciências Humanas, Universidade Federal do Rio Grande do Sul, Porto Alegre, 2015.

CAMINO, Leoncio et al. Repertórios discursivos de estudantes universitários sobre cotas raciais nas universidades públicas brasileiras. Psicologia e Sociedade, Florianópolis, v. 26, n. especial, p. 117-128, jan. 2014. Disponível em: http://www.scielo.br/pdf/psoc/v26nspe/13.pdf. Acesso em: 5 abr. 2017.

CERQUEIRA, Daniel et al. (org.). Atlas da violência: 2017. Disponível em: http://www.ipea.gov.br/portal/images/170602_atlas_da_violencia_2017.pdf. Acesso em: 5 abr. 2018.

CRISOSTOMO, Maria Aparecida dos Santos; REIGOTA, Marcos Antonio dos Santos. Professoras universitárias negras: trajetórias e narrativas. Avaliação: Revista da Avaliação da Educação Superior, Campinas, Sorocaba, v. 15, n. 2, p. 93-106, jul. 2010. Disponível em:

http://www.scielo.br/scielo.php?pid=S1414-40772010000200005\&script=sci_abstract\&tlng=pt. Acesso em: 5 abr. 2018.

DAFLON, Verônica Toste; FERES JÚNIOR, João; CAMPOS, Luiz Augusto. Ações afirmativas raciais no ensino superior público brasileiro: um panorama analítico. Cadernos de Pesquisa, São Paulo v. 43, n. 148, p. 302-327, abr. 2013. Disponível em: http://www.scielo.br/scielo.php?pid=S010015742013000100015\&script=sci_abstract\&tlng=pt. Acesso em: 5 abr. 2017.

FONSECA, Leandro de Campos. Estudo de caso dos repertórios interpretativos empregados na construção de posicionamentos contrários ao sistema de cotas raciais nas universidades públicas brasileiras em comentários na internet. 2014. 258p. Dissertação (Mestrado em Psicologia Social) Instituto de Psicologia, Universidade de São Paulo, São Paulo, 2014.

GOTO, Vanessa Strowitzki. A questão social do negro brasileiro e o dilema entre redistribuição e reconhecimento: uma análise das cotas raciais nas universidades públicas. 2014. 152p. Dissertação (Mestrado em Ciências Sociais) - Faculdade de Filosofia e Ciências de Marília, Universidade Estadual Paulista, Marília, 2014.

GRISA, Gregório Durlo. Ações afirmativas na UFRGS: racismo, excelência acadêmica e cultura do reconhecimento. 2015. 220p. Tese (Doutorado em Educação) - Faculdade de Educação, Universidade Federal do Rio Grande do Sul, Porto Alegre, 2015.

GUEDES, Claudia Rosane. A imagem de mulheres negras universitárias: a silhueta esculpida durante o processo de formação. 2012. 139p. Dissertação (Mestrado em Enfermagem) - Faculdade de Enfermagem, Universidade do Estado do Rio de Janeiro, Rio de Janeiro, 2012.

INSTITUTO BRASILEIRO DE GEOGRAFIA E ESTATISTICA (IBGE). 2010. Disponível em: https://www.ibge.gov.br/. Acesso em: 12 abr. 2018. 
SILVA, Marcos Antonio Batista da. Pesquisas contemporâneas sobre a condição do negro no Brasil e a universidade: tendências e debates (1988-2016).

LEWANDOWSKI, Enrique Ricardo. Compatibilidade do sistema de reserva de cotas étnico-raciais nas universidades públicas com a Constituição de 1988, segundo decisão do Supremo Tribunal Federal proferida na ADPF no 186/DF. In: A CONSTITUIÇÃO de 1988 na visão dos ministros do Supremo Tribunal Federal. Brasília: Supremo Tribunal Federal, 2013. p. 115-148.

LIMA, Marcus Eugênio Oliveira; NEVES, Paulo Sérgio da Costa; SILVA, Paula Bacellar e. A implantação de cotas na universidade: paternalismo e ameaça à posição dos grupos dominantes. Revista Brasileira de Educação, Rio de Janeiro, v. 19, n. 56, p. 141-163, mar. 2014. Disponível em: http://www.scielo.br/scielo.php?pid=s1413-24782014000100008\&script=sci_abstract\&tlng=pt. Acesso em: 7 abr. 2018.

LIMA, Maria Luciene Ferreira. Políticas públicas no ensino superior: ações afirmativas na UFPB. 2014. 152p. Dissertação (Mestrado em Direitos Humanos) - Universidade Federal da Paraíba, João Pessoa, 2014.

LOPES, Toni Ronei. Ações afirmativas: a igualdade e o acesso pleno à educação superior dos grupos sociais historicamente excluídos. 2014. 218p. Dissertação (Mestrado em Educação) - Centro de Educação, Universidade Federal de Santa Maria, Santa Maria, RS, 2014.

MACHADO, Isabel. Professoras negras na UERJ e cotidianos curriculares, a partir dos primeiros tempos do acervo fotográfico J. Vitalino. 2011. 146p. Dissertação (Mestrado em Educação) Universidade do Estado do Rio de Janeiro, Rio de Janeiro, 2011.

MELO, Janaína Farias de. Significado do sistema de cotas para o ingresso no ensino superior para estudantes negros de escola pública de Fortaleza. 2016. 106p. Dissertação (Mestrado em Psicologia) Centro de Humanidades, Universidade Federal do Ceará, Fortaleza, 2016.

NATEL, Elisabeth Santos. Educação das relações étnico-raciais: as sagas e resiliências das mulheres negras profissionais: em três ambientes universitários. 2014. 181p. Dissertação (Mestrado em Ciências Sociais) - Universidade do Vale do Rio dos Sinos, São Leopoldo, RS, 2014.

OSORIO, Rafael Guerreiro. Classe, raça e acesso ao ensino superior no Brasil. Cadernos de Pesquisa, São Paulo, v. 39, n. 138, p. 867-880, dez. 2009. Disponível em: http://www.scielo.br/scielo.php?pid=s0100-15742009000300009\&script=sci_abstract\&tlng=pt Acesso em: 12 abr. 2017.

PAIXÃO, Marcelo. Relatório anual das desigualdades raciais no Brasil: 2009-2010. Rio de Janeiro: Geledés Instituto da Mulher Negra, 2010. Disponível em: https://www.geledes.org.br/marcelo-paixaorelatorio-anual-das-desigualdades-raciais-brasil/. Acesso em: 12 mar. 2018.

PASSOS, Ana Helena Ithamar. Reflexão acadêmica e afrodescendência: um estudo da contribuição de três núcleos de pesquisa de universidades do Rio de Janeiro para o enfrentamento do racismo no Brasil. 2006. 100p. Dissertação (Mestrado em Serviço Social) - Departamento de Serviço Social, Pontifícia Universidade Católica do Rio de Janeiro, Rio de Janeiro, 2006.

PASSOS, Joana Célia dos. Relações raciais, cultura acadêmica e tensionamentos após ações afirmativas. Educação em Revista, Belo Horizonte, v. 31, n. 2, p. 155-182, jun. 2015. Disponível em: http://www.scielo.br/scielo.php?pid=S0102-46982015000200155\& script= sci abstract\&tlng=pt. Acesso em: 12 abr. 2018.

PEREIRA, Waléria Furtado. Prática de inclusão na universidade: representações de professores e estudantes. 2011. 275p. Tese (Doutorado em Educação) - Faculdade de Educação, Universidade de São Paulo, São Paulo, 2011. 
PINHEIRO, Adevanir Aparecida. Identidade étnico-racial e universidade: a dinâmica da visibilidade da temática afrodescendente e as implicações eurodescendentes, em três instituições de ensino superior no sul do país. 2011. 340p. Tese (Doutorado em Ciências Sociais) - Universidade do Vale do Rio dos Sinos, São Leopoldo, RS, 2011.

SANTOS, Sérgio Pereira dos. “Os 'intrusos' e os 'outros' quebrando o aquário e mudando os horizontes": as relações de raça e classe na implementação das cotas sociais no processo seletivo para cursos de graduação da Ufes, 2006-2012. 2014. Tese (Doutorado em Educação) - Centro de Educação, Universidade Federal do Espírito Santo, Vitória, 2014.

SANTOS JÚNIOR, Amilton dos. Identidade, discriminação e saúde mental em estudantes universitários. 2011. 304 f. Dissertação (Mestrado em Ciências Médicas) - Faculdade de Ciências Médicas, Universidade Estadual de Campinas, Campinas, SP, 2011.

SILVA, Marcos Antonio Batista da. Discursos étnico-raciais proferidos por pesquisadores/as negros/as na pós-graduação: acesso, permanência, apoios e barreiras. 2016. 240p. Tese (Doutorado em Psicologia) - Pontifícia Universidade Católica de São Paulo, São Paulo, 2016.

SYSS, Ahyas (org.). Diversidade étnico-racial e educação superior brasileira: experiências de intervenção. Rio de Janeiro: Quartet, 2008.

TEIXEIRA, Moema de Poli. Negros na universidade: identidade e trajetórias de ascensão social no Rio de Janeiro. Rio de Janeiro: Pallas, 2003.

THOMPSON, John Brookshire. Ideologia e cultura moderna: teoria social crítica na era dos meios de comunicação de massa. Petrópolis, RJ: Vozes, 2011.

VON DENTZ, Schirlei Russi. Vozes das mulheres negras cotistas da Universidade Federal de Santa Catarina: 2010-2014. 2016. 200p. Dissertação (Mestrado em Educação) - Centro de Ciências da Educação, Universidade Federal de Santa Catarina, Florianópolis, 2016. 